\title{
Deformation in transcurrent and extensional environments with widely spaced weak zones
}

\author{
Eun-seo Choi and Michael Gurnis \\ Seismological Laboratory, California Institute of Technology, Pasadena, California, USA \\ Received 19 August 2002; revised 19 November 2002; accepted 2 December 2002; published 25 January 2003.
}

[1] Previous mechanical models of the western U.S. have concluded that plate boundary forces cannot generate farfield deformation. Such models have ignored preexisting large-scale lithospheric strength variations, an assumption that appears to be inconsistent with seismically determined variations in lithospheric structure. We have formulated a three-dimensional viscous flow model with imposed plate motions, but include lateral zones of low viscosity. These models show that strain rates are concentrated in weak zones with adjacent blocks experiencing little deformation. Deformation can extend far inboard of plate boundaries, contrary to the result of previous studies with rheologically homogeneous plates, and apparently compatible with the variation is seismic velocity and GPS determined deformations in western U.S. These results suggest that plate boundary forces cannot be neglected in the deformation of the western U.S., including the Cenozoic extension of the Basin and Range Province. INDEX TERMS: 8110 Tectonophysics: Continental tectonics-general (0905); 8109 Tectonophysics: Continental tectonics-extensional (0905); 8120 Tectonophysics: Dynamics of lithosphere and mantle-general. Citation: Choi, E.-s., and M. Gurnis, Deformation in transcurrent and extensional environments with widely spaced weak zones, Geophys. Res. Lett., 30(2), 1076, doi:10.1029/2002GL016129, 2003.

\section{Introduction}

[2] Plate boundary and buoyancy forces could be significant in the extensional deformation of western U.S., but since the deformation of this region is probably the result of a dynamic balance between multiple forces, attempts to determine which force dominates have been inconclusive. Since continental crust is pervasively faulted, England and Jackson [1989] and subsequent workers, have assumed that at sufficiently large scales, the crust can be approximated as a non-linear viscous fluid. Making this assumption, with a single power law rheology approximating the vertically averaged lithosphere, Sonder et al. [1986] showed that boundary velocity decayed rapidly with distance away from the margin and only a narrow region near either a transform or divergent boundary could be deformed. Sonder and Jones [1999] reached the conclusion that buoyancy forces dominate the western US force balance by first showing that buoyancy forces are sufficiently large to cause the deformation and then by arguing that the influence of plate boundary forces is negligible within the continental interior. Using a thin viscous sheet model with velocity boundary conditions representing Pacific-North American transform motion, they rejected plate boundary forces as a viable mechanism for Basin and Range extension and concluded that plate boundary forces could not have generated the inferred strains through the western U.S.

[3] However, these models ignored lateral heterogeneities in lithospheric strength. Since the mantle lid is the strongest part of lithosphere, its thickness is closely related to the strength of lithosphere. Seismic studies through the Basin and Range Province have shown marked differences in the thickness of the mantle lid (Figure 1) that should presumably be reflected in the strength of the lithosphere. For example, by compiling seismic refraction profiles, Braile et al. [1989] showed that there were lower seismic velocities within the upper mantle beneath the northern Basin and Range while seismic velocities under the Sierra Nevada and Colorado plateau where higher than average. York and Helmberger [1973] detected a band of low seismic velocities across the northern Basin and Range from the middle of Utah and traversing southern Nevada and southern California. This upper mantle structure is consistent in a more recent tomographic study by Humphreys and Dueker [1994b]. This low velocity band may be more aptly described as a thin upper mantle lid beneath the Basin and Range-Colorado Plateau boundary, which was revealed by teleseismic $\mathrm{P}$ wave travel times [Zandt et al., 1995]. Melbourne and Helmberger [2001] showed that lithospheric lid thickness varies significantly from $55 \mathrm{~km}$ along the coast of California to near zero thickness along eastern California.

[4] We reappraise the argument against plate boundary forces and show that previous studies may not have adequately considered an important aspect of regional structure. New models presented here include lateral variations in viscosity to reflect the observed seismic velocity variations as a proxy for lithospheric strength. With the new formulation, we argue that plate boundary forces could generate substantial deformation within continental interiors in both strikeslip and extensional environments and that plate boundary forces should still be considered as a viable component in the force balance of western U.S. over the Cenozoic.

\section{Model Setup}

[5] A three-dimensional (3D) spherical finite element method [Zhong et al., 2000] is used to model the influence of a discontinuous viscosity distribution on lithospheric deformation. Using the Boussinesq approximation, the equations of mass and momentum conservation are:

$$
\begin{gathered}
\nabla \cdot \mathbf{u}=0 \\
-\nabla P+\eta \nabla^{2} \mathbf{u}+\alpha \rho_{0} g\left(T-T_{0}\right) \mathbf{e}_{3}=0
\end{gathered}
$$




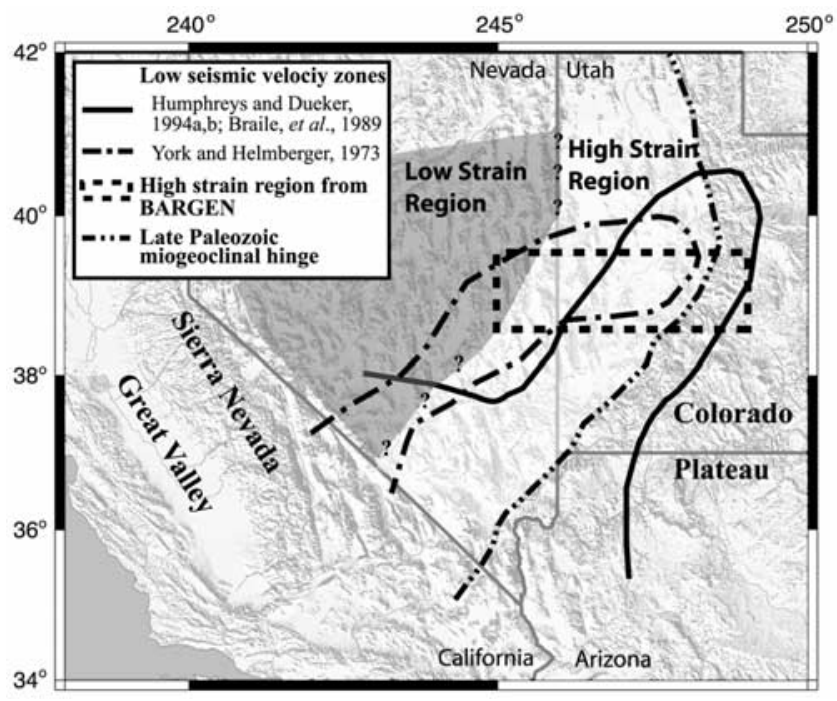

Figure 1. Shaded relief map of the northern Basin and Range, roughly showing the locations of low seismic velocity zones [York and Helmberger, 1973; Braile et al., 1986; Humphreys and Deuker, 1998b] and of the high strain region found with the BARGEN data [Niemi et al., 2001]. It also shows a probable division of the northern Basin and Range into regions of relatively high strain (with brighter shades) and low strain (with darker shades).

where $\mathbf{e}_{3}$ is a unit vector in the radial direction; $\mathbf{u}$ is the velocity; $T$ and $T_{0}$ are the temperature and the reference temperature, respectively; $P$ is the pressure; $\eta$ is the viscosity; $\alpha$ is the coefficient of thermal expansion; $\rho_{0}$ is the mantle density; and $\boldsymbol{g}$ is the acceleration of gravity. Viscosity is both temperature- and position-dependent:

$$
\eta(T, \varphi, r)=C(\varphi, r) \eta_{0} \exp \left(\frac{c_{1}}{c_{2}+T / T_{0}}-\frac{c_{1}}{c_{2}+1.0}\right)
$$

where $\eta_{0}$ is the viscosity when $T=T_{0} ; \varphi$ and $\mathrm{r}$ are the polar and the radial coordinates, respectively; $c_{1}$ and $c_{2}$ are constants chosen so that the viscosity at $T=0^{\circ} \mathrm{C}$ is higher than $\eta_{0}$ by two orders of magnitude. The role of $C(\varphi, r)$ is the spatially varying part of the viscosity. Model parameters are given in Table 1.

[6] The spatial extent of the model domain is $60^{\circ}$ in longitude, $40^{\circ}$ in latitude, and $637 \mathrm{~km}$ in depth (Figure 2a). Only the inner region, $30^{\circ} \times 20^{\circ} \times 637 \mathrm{~km}$, is of interest with the outer region used to reduce the influence of the vertical walls. Velocity boundary conditions enforce plate motion on the top within the inner region (within region A,

Table 1. Model Parameters

\begin{tabular}{cll}
\hline Symbol & \multicolumn{1}{c}{ Name } & \multicolumn{1}{c}{ Value } \\
\hline$\alpha$ & Coefficient of thermal expansion & $2 \times 10^{-5} \mathrm{~K}^{-1}$ \\
$\rho_{0}$ & Reference density & $3300 \mathrm{Kg} / \mathrm{m}^{3}$ \\
$\kappa$ & Thermal diffusivity & $10^{-6} \mathrm{~m} / \mathrm{s}$ \\
$\eta_{0}$ & Reference viscosity & $10^{21} \mathrm{~Pa} \cdot \mathrm{s}$ \\
$C_{1}$ & Constant for viscosity & 9.50614 \\
$\mathrm{C}_{2}$ & Constant for viscosity & 1.02126 \\
$T_{0}$ & Reference (mantle) temperature & $1300^{\circ} \mathrm{C}$ \\
$T_{1}$ & Surface temperature & $0^{\circ} \mathrm{C}$ \\
\hline
\end{tabular}

Figure 2a). By creating a "transform boundary" along the equator with the length of the boundary being $\mathrm{L}$, we can directly compare our result to earlier thin viscous sheet models with homogeneous rheologies through parameter conversion [Sonder et al., 1986]. The temperature distribution is from a half-space cooling model defining a $100 \mathrm{~km}-$ thick thermal lithosphere (Figure $2 b$ ) and is horizontally uniform. The coefficient, $C(\varphi, r)$, is dependent on the polar angle, $\varphi$, allowing weak zones through the lithosphere at different distances from the plate boundary (Figure 2c).

[7] The weak zone in spherical shell models is defined as a narrow region of lower viscosity compared to adjacent regions. The ratio of viscosity of the weak zone to that of the adjacent normal region at a certain depth is denoted as $\eta_{\text {weak }} / \eta_{\text {normal }}$. The zone of reduced viscosity extends to the base of the lithosphere, is $210 \mathrm{~km}$ in width, and is of the same length as the longitudinal dimension of the outer region $(\sim 6672 \mathrm{~km}$, Figure $2 \mathrm{a})$. There are two controlling parameters for the weak zone: the viscosity ratio and its distance from the plate margin. $\eta_{\text {weak }} / \eta_{\text {normal }}$ varies from $10^{-1}$ and $10^{-4}$. Three locations for the weak zone are
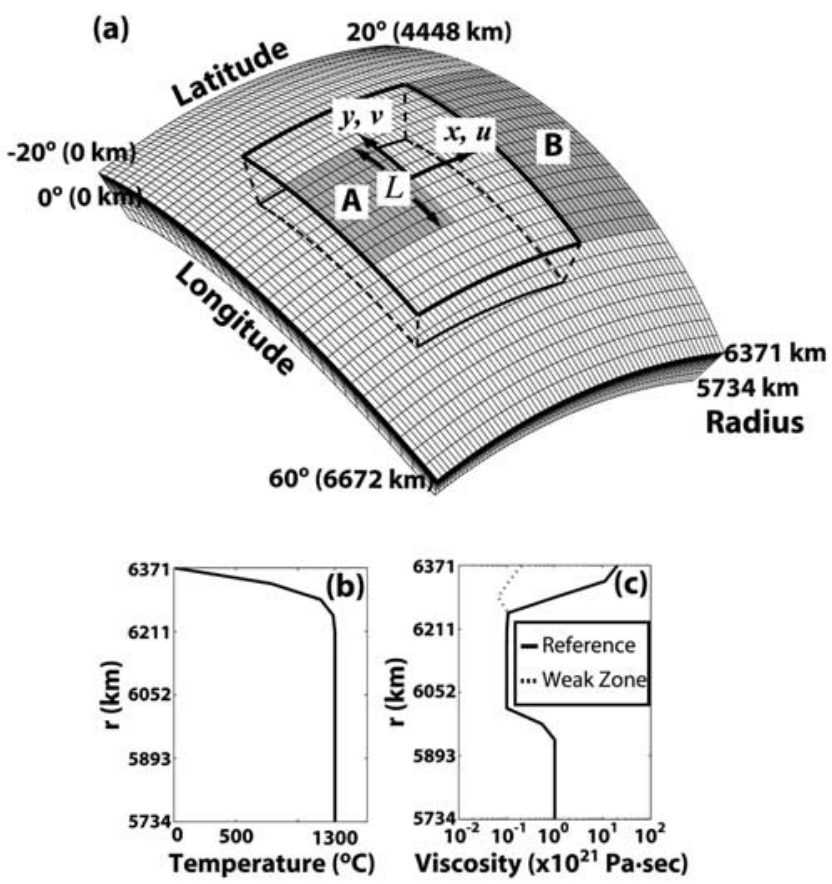

Figure 2. (a) Coordinates of the finite element mesh and configuration for boundary conditions. The inner region is the volume outlined by thick solid and dashed lines. $\mathrm{x}$-axis is along the $30^{\circ}$ meridian and $\mathrm{y}$ - axis along the equator. $u$ and $v$ are velocity tangential to $\mathrm{x}-$ and $\mathrm{y}$-axis, respectively. Velocity boundary conditions are applied on the regions shaded with dark gray: $u=0.0, v=v_{0}=5.0 \mathrm{~cm} / \mathrm{yr}$ in region A, while $u=v=0$ in region B. $v=0.0$ and $\partial u / \partial x=0.0$ on the vertical boundaries. The mesh has 32 elements in longitude and 64 in latitude (with regular spacing) and 16 in depth (refined through the upper $100 \mathrm{~km}$ ) (b) Variations of temperature with depth. (c) Viscosity variation with depth. Viscosity for the blocks is drawn in solid line. Viscosity for a weak zone with viscosity ratio $\eta_{\text {weak }} / \eta_{\text {normal }}$ of $10^{-2}$ is drawn in dashed line. 

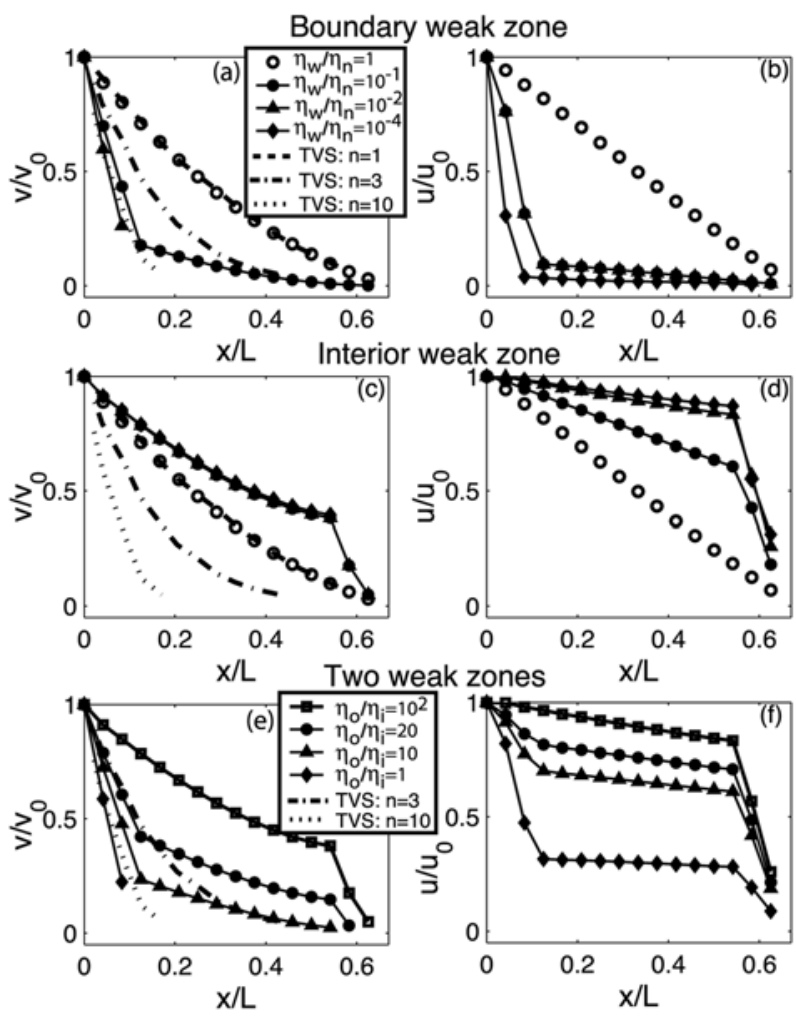

Figure 3. Velocity profiles for transform boundary conditions and for normal velocity boundary conditions. (left) $y$-velocity, $v$, plotted as a function of distance from the transform boundary, $x . v$ is normalized with respect to $v_{0}=5$ $\mathrm{cm} / \mathrm{yr}$, the boundary velocity, and $x$ with respect to $L$. (right) Normalized $x$ velocity, $u / u_{0}$, versus normalized distance from the plate boundary, $x / L$, for the normal velocity boundary conditions: $u=u_{0}=-5 \mathrm{~cm} / \mathrm{yr}$ and $v=0.0$. Different symbols are used for numerical solutions with different viscosity ratio of the weak zone to the normal value $\left(\eta_{w} / \eta_{n}\right)$. For comparison, analytical solutions for thin viscous sheet model (TVS) with the corresponding velocity boundary condition [England et al., 1985] are plotted with different types of lines. (a, b) The weak zone is on the boundary between the two plates, (c, d) at $x / L=\sim 0.6$, far inboard of the plate. (e, f) Models with two weak zones: the outer one at the plate boundary and the interior one at $x / a=$ $\sim 0.6$, of which viscosities are $\eta_{o}$ and $\eta_{i}$, respectively. While $\eta_{i} / \eta_{n}$ fixed at $10^{-2}, \eta_{o} / \eta_{i}$ changed from 1 to $10^{2}$.

considered: on the transform boundary (Figures 3a and 3b), far inboard of the margins (about 0.6L), meant to represent the miogeoclinal hinge of the North American Plate (Figure $3 \mathrm{c}$ and $3 \mathrm{~d}$ ). Noting that a natural weak zone is developed at the plate boundary in thin viscous sheet models, we also consider models with two weak zones: one at the plate boundary and the other at $0.6 \mathrm{~L}$ (Figures $3 \mathrm{e}$ and $3 \mathrm{f}$ ).

\section{Results}

[8] The results from the spherical shell models show a dependence of deformation on viscosity reduction and weak zone position. We first consider the influence of the weak zones in spherical shell models in which plate motion along the boundary is strike-slip. We show the component $(v)$ of velocity parallel to the strike-slip margin (see Figure 2a for a coordinate layout), normalized by the boundary velocity $\left(v_{0}\right)$, versus normalized distance $(x / L)$ from the plate boundary along the $30^{\circ}$ meridian. The gradient of velocity is particularly steep within the weak zones while they are mild outside of the weak zones, especially for models with the weak zone on the boundary between the two plates. In other words, there are mildly deforming blocks separated by shear zones, a conclusion which is not particularly sensitive to the magnitude of the viscosity reduction once the velocity has been reduced by one order of magnitude (Figures $3 \mathrm{a}$ and $3 \mathrm{c}$ ).

[9] There has also been a normal component to the motion of the Pacific plate outboard of northern Basin and Range province [e.g. Atwater and Stock, 1998; Snow and Wernicke, 2000] and so a second boundary condition is considered, which can also be compared with earlier models (Figures $3 \mathrm{~b}$ and $3 \mathrm{~d}$ ). With purely normal velocity boundary conditions $\left(u_{0}=-5 \mathrm{~cm} / \mathrm{yr}\right.$ and $\left.v=0.0\right)$ applied on the region A (Figure 2a), the normal component of velocities for each configuration of weak zone shows a similar pattern compared with the transform boundary condition: strain concentration in weak zone between mildly deforming blocks.

[10] It is noteworthy that the behavior of these numerical models is in sharp contrast to the analytical solutions for a semi-infinite, thin viscous sheet model for a lithosphere with a non-linear rheology. For example, in the weak-zone model with the weak zone placed far inboard of the margin (at $x / L=\sim 0.6$ Figure 3c), the velocity decreases to $50 \%$ of the boundary value at $x / L=\sim 0.3$, while in the thin sheet model with $n>1$ the corresponding velocity is essentially zero. The characteristic length scale of velocity decay is even larger for the normal velocity boundary condition: the decrease of velocity is only about $10 \%$ at $x / L=\sim 0.3$ for the model with the weak zone far inboard of the boundary (Figure $3 \mathrm{~d}$ ). In thin viscous sheet models, as the nonlinearity of the viscosity increases (i.e. as the exponent, $n$, increases), the characteristic length scale of the decay of velocity decreases [England et al., 1985; Sonder et al., 1986]. However, lowering the viscosity within the weak zone leads to an increase in characteristic length scale over which the deformation is distributed.

[11] Models with two weak zones (Figures 3e and 3f) show the importance of incorporating pre-existing strength variations in the lithosphere even though a non-Newtonian rheology may result in a weak plate boundary. A weak plate boundary zone, simulating the effect of a power-law rheology, does take up a large amount of deformation, but the interior weak zone still deforms faster than the strong interior region. This deformation pattern becomes obvious in models with a relatively strong strike-slip boundary (Figure 3e), or with imposed normal velocity boundary conditions (Figure 3f). Thus, our results are relevant to the deformation of the western U.S., because this region has a significant component of extension.

\section{Discussion}

[12] In order to verify the importance of either plate boundary forces or buoyancy forces, heterogeneities in the lithospheric strength need to be properly incorporated into 
deformation models. Variations in lithospheric strength is generally critical for understanding the dynamics of lithospheric deformation, but studies such as Neil and Houseman [1997] and Ellis et al. [1998] have only applied such complications to compressional settings. As for the Basin and Range province, Sonder and Jones [1999] treated the Sierra-Nevada and Great Valley block as a relatively rigid area in a thin-sheet model, showed that deformation remained concentrated near the transform boundary, and argued that the inclusion of strong regions did not alter the decay of the plate boundary forces into continental interiors. However, their specific lithospheric strength structures did not incorporated all of the crustal and the upper mantle features suggested by seismic studies.

[13] The eastern part of the northern Basin and Range appears to be different in terms of its seismically determined crust and upper mantle compared to adjacent regions. The eastern Basin and Range (at $39^{\circ}-40^{\circ} \mathrm{N}$ ) with a width of $300-$ $\mathrm{km}$ and located west of the Colorado plateau coincides with the northern end of a low velocity zone [York and Helmberger, 1973; Humphreys and Dueker, 1994a] (Figure 1). The association of this seismic low velocity region with high heat flow $\left(\sim 120 \mathrm{~mW} / \mathrm{m}^{2}\right)$ and recent active volcanism (along the St. George volcanic trend) lead Humphreys and Dueker [1994b] to suggest the existence of partial melts in the upper mantle. They thought about $1-3 \%$ of partial melt would be necessary to explain the $\sim 4 \%$ of $\mathrm{P}$ wave velocity reduction. Since partial melts generally reduce viscosity, the heat flow and seismic studies support the presence of a weak zone beneath the eastern part of the northern Basin and Range. This putative weak zone is geometrically similar to our models with the weak zone far inboard of plate boundary. Consequently, based on our models (Figure 3) we would expect that this region to be straining much faster compared to the Basin and Range further to the west or the Colorado Plateau further to the east.

[14] This interpretation is consistent with recent geodetically determined strain distributions. With the Basin and Range Geodetic Network (BARGEN) [Wernicke et al., 2000], Niemi et al. [2000] found a concentration of strain in the eastern one-third of the northern Basin and Range and negligible strain in the western part of the northern Basin and Range (except near to the plate boundary) (Figure 1). Specifically, they found that displacements varied linear with distance from the western boundary of the Colorado Plateau along $39^{\circ} \mathrm{N}$ in the area that had previously been mapped as a seismically low velocity region. These GPS data show that the central part of the northern Basin and Range behaves as a relatively rigid block, while strain is distributed mostly over the possibly weaker eastern part.

[15] These results imply that plate boundary forces could be important even in the far-field deformation of a continent, when large-scale lateral variations in lithospheric strength are present within a continent. Since the rapid exponential decay of deformation away from the boundary has been used as an argument against plate boundary forces in continental deformations, we need to further investigate the combined influence of plate boundary forces and heterogeneous rheology.

[16] Acknowledgments. This is contribution 8885 of the Division of Geological and Planetary Sciences, Caltech. This work has been supported by NSF Grant EAR-0107137. We thank M. Simons, N. McQuarrie and L. Lavier for helpful comments on an earlier version of the paper.

\section{References}

Atwater, T., and J. Stock, Pacific-North America plate tectonics of the Neogene southwestern United States: An update, International Geology Review, 40, 375-402, 1998.

Braile, L. W., W. J. Hinze, R. R. B. von Frese, and G. R. Keller, Seismic properties of the crust and uppermost mantle of the conterminous United States and adjacent Canada, in Geophysical framework of the continental United States, Geol. Soc. Am. Mem. 172, edited by L. C. Pakiser and W. D. Mooney, pp. 655-680, Geological Society of America, Boulder, Colo., 1989.

Ellis, S., C. Beaumont, R. A. Jamieson, and G. Quinian, Continental collision including a weak zone: The vise model and its application to the Newfoundland Appalachians, Can. J. Earth Sci., 35, 1323-1346, 1998.

England, P., G. Houseman, and L. Sonder, Length scales for continental deformation in convergent, divergent, and strike-slip environments: Analytical and approximate solutions for a thin viscous sheet model, J. Geophys. Res., 90, 3551-3557, 1985.

England, P., and J. Jackson, Active deformation of the continents, Ann. Rev. Earth Planet. Sci., 17, 197-226, 1989.

Humphreys, E. D., and K. G. Dueker, Western U.S. upper mantle structure, J. Geophys. Res., 99, 9615-9634, 1994a.

Humphreys, E. D., and K. G. Dueker, Physical state of the western U.S. upper mantle, J. Geophys. Res., 99, 9635-9650, 1994b.

Melbourne, T., and D. Helmberger, Mantle control of plate boundary deformation, Geophys. Res. Lett., 28, 4003-4006, 2001.

Neil, E. A., and G. A. Houseman, Geodynamics of the Tarim Basin and the Tian Shan in central Asia, Tectonics, 16, 571-583, 1997

Niemi, N. A., B. Wernicke, A. M. Fredrich, M. Simons, R. A. Bennett, and J. L. Davis, BARGEN continuous GPS data across the eastern Basin and Range province, and implications for fault system dynamics, Geophys. J. Int., submitted, 2001.

Snow, J. K., and B. P. Wernicke, Cenozoic tectonism in the central Basin and Range: Magnitude, rate, and distribution of upper crustal strain, Am. J. Sci., 300, 659-719, 2000.

Sonder, L. J., P. C. England, and G. A. Houseman, Continuum calculations of continental deformation in transcurrent environment, J. Geophys. Res., 91, 4797-4810, 1986.

Sonder, L. J., and C. H. Jones, Western Unites States extension: How the west was widened, Annu. Rev. Earth Planet. Sci., 27, 417-462, 1999.

Wernicke, B., A. M. Fredrich, N. A. Niemi, R. A. Bennett, and J. L. Davis, Dynamics of plate boundary fault systems from Basin and Range Geodetic Network (BARGEN) and geologic data, GSA Today, 10, 1-7, 2000.

York, J. E., and D. V. Helmberger, Low-velocity zone variations in the southwestern United Sates, J. Geophys. Res., 78, 1883-1886, 1973.

Zandt, G., S. C. Myers, and T. C. Wallace, Crust and mantle structure across the Basin and Range-Colorado plateau boundary at $37^{\circ}$ latitude and implications for Cenozoic extensional mechanism, J. Geophys. Res., 100, $10,529-10,548,1995$.

Zhong, S., M. T. Zuber, L. Moresi, and M. Gurnis, Role of temperaturedependent viscosity and surface plates in spherical shell models of mantle convection, J. Geophys. Res., 105, 11,063-11,082, 2000.

E.-s. Choi and M. Gurnis, Seismological Laboratory, California Institute of Technology, Pasadena, CA 91125, USA. (ces74@gps.caltech.edu) 